


\title{
Paisaje y videoarte en la era del Antropoceno: el paisaje ecologista
}

\author{
Landscape and Video Art in the Anthropocene Era: The Ecologist Landscape
}

\author{
Cristina Sanz Martín \\ Universidad de Málaga, España \\ cristinasanz@usal.es
}

https://orcid.org/0000-0002-5225-6847

Recepción: 09/05/2020 |Aceptación: 07/07/2020

\section{Resumen}

Desde los sesenta, el paisaje ha experimentado un resurgimiento en el arte, sin embargo, se sigue representando e interpretando, principalmente, a través de los códigos pictóricos heredados de la tradición paisajística moderna. Tras analizar el panorama artístico contemporáneo, y, en particular, las propuestas videoartísticas, hemos detectado el surgimiento de un nuevo paisaje que se adapta a los códigos formales y conceptuales que representan a la sociedad de su tiempo, como, por ejemplo, la imagen en movimiento, el lenguaje audiovisual o la sensación inmersiva. Así como a las preocupaciones que turban a la sociedad contemporánea. Este trabajo trata sobre las prácticas que aúnan videoarte y paisaje, particularizando en aquellas que se centran en el -que hemos denominado- paisaje "ecologista".

\section{Abstract}

Since the sixties, the Landscape has experienced a resurgence in the arts. However, it continues to be represented and interpreted mainly through pictorial codes inherited from the modern landscape tradition. Our analysis of the contemporary art scene, with a focus on video art proposals, reveals the emergence of a new landscape that adapts to formal and conceptual codes as a reflection of contemporary society. Examples include the moving image, audiovisual language or a feeling of immersion, as well as society's concerns. This study addresses the practices that combine video art and landscape, focusing on those that feature what we have named "ecological" landscapes.
Palabras clave

Paisaje
Arte
Videoarte
Ecologismo
Contemporáneo
Antropoceno

Keywords

Landscape

Art

Video Art

Ecologism

Contemporary

Anthropocene 
La contemplación del mundo exterior siempre será clave para la supervivencia de cualquier especie y, por lo tanto, es un acto instintivo. Gianfranco Foschino'.

\section{Introducción}

En las últimas décadas, especialmente desde los sesenta, el paisaje ha experimentado un resurgimiento en el arte contemporáneo. Mas, paradójicamente, a la vez, ha ido sufriendo una cierta despreocupación por parte de la Historia del Arte en cuanto a su identidad y autonomía, y una apropiación errada por parte de muy diversas disciplinas, desarraigándolo de su verdadero sentido y otorgándole nuevos y dispares significados que, preocupantemente, contribuyen a la confusión identitaria de las nuevas prácticas artísticas contemporáneas. Parece que hemos olvidado que el paisaje surgió como un género pictórico, con su correspondiente definición y con sus características propias como corresponde a todo género. Hoy día el paisaje se ha expandido más allá del formato pictórico de la tradición moderna, pero: ¿Cuál es el paisaje que representa a la era contemporánea? ¿cómo son los códigos, la narrativa, el lenguaje y la estética de aquellos que están creando una nueva tradición paisajista que sí representa a los individuos del Antropoceno?². La hipótesis que plantea esta investigación es que ha surgido un nuevo tipo de paisaje. Un nuevo paisaje que los historiadores del arte parecemos haber obviado hasta ahora y que dista mucho de los códigos estéticos y conceptuales de la tradición paisajística moderna.

A lo largo de nuestra investigación hemos identificado diferentes tipos de paisajes en el arte contemporáneo, empero en este artículo nos centraremos en estudiar únicamente una tipología, aquel que hemos denominado "paisaje ecologista". Un nuevo tipo de paisaje genuinamente contemporáneo que surge en respuesta a la realidad única de nuestra sociedad. Revisaremos este amplio panorama a través del estudio de la obra de tres videoartistas, cuyos trabajos -de manera intencionada o no-, por su naturaleza, toman una dimensión de índole casi activista. Se trata de artistas que entienden la naturaleza como un gran sistema armónico en el que nosotros representamos solo un elemento más y que establecen con ella relaciones de respeto y aprendizaje, alejándose de la dominación y la destrucción que reina hoy. Sus trabajos pretenden remover el

1. Esta cita pertenece a una entrevista aún inédita realizada al artista en enero de 2019. La entrevista será publicada junto a la investigación que motiva este artículo.

2. Este término será detenidamente tratado en el segundo apartado, "La praxis". 
pensamiento de los espectadores y contribuyen a instaurar una conciencia ecologista colectiva en una sociedad que ha creado un mundo artificial paralelo desconectándonos, así, de nuestro ecosistema originario. Estos artistas son conscientes de los riesgos de la era antropocénica y tratan de hacer ver a la sociedad los resultados presentes y futuros de las consecuencias de su impacto ambiental.

Resulta preocupante ver cómo en los últimos años se ha asumido de forma colectiva una idea errada del concepto de paisaje. Con notoria frecuencia se concibe al paisaje como una realidad geográfica. Sin embargo, lo que resulta aún más alarmante es la asiduidad con la que encontramos estas ideas en la disciplina artística. A diferencia de lo frecuentemente asumido, el paisaje no puede ser una realidad física porque no existe per se. Hoy en día el término se ha diluido hasta abarcar campos tan dispares como el turismo, la ecología, el urbanismo, la sostenibilidad o la sociología ${ }^{3}$, como si hubiésemos olvidado que el paisaje es un género que nació con las bellas artes. Otra de las problemáticas que motivaron este trabajo es que gran parte de las prácticas que hemos analizado a lo largo de esta investigación son, relativamente, muy recientes, la gran mayoría de la última década. Paradójicamente, estos nuevos paisajes sí han entrado dentro del circuito del arte: se escribe sobre ellos en magazines -que se acercan más al periodismo que a la ciencia-, los artistas han llegado a las galerías, participan en las ferias de arte de todo el mundo y comienzan a formar parte de los fondos de los mejores museos de arte contemporáneo como el MoMA. Pero se ha detectado un gran vacío en cuanto a un estudio riguroso de las mismas desde la disciplina de la Historia del Arte. Existe una necesidad urgente de que estos nuevos paisajes sean estudiados desde el ámbito académico.

Hablar de paisaje implica hablar de cultura, historia, tradición, literatura, creencias religiosas, filología, percepción, ciencia, filosofía, poesía, bellas artes, especialmente de historia de la pintura, pero también de fotografía. El paisaje es un conglomerado de diversas disciplinas. Para existir, reclama un esfuerzo perceptivo, determinado, además, por la condición socioeconómica del individuo y su bagaje cultural. El paisaje es un constructo creado a través de la tradición cultural que se fue desarrollando con el paso de los siglos gracias, también, al desarrollo científico y artístico. Es una ecuación formada, por un lado, por la naturaleza y el ser humano y, por el otro, por el sentimiento, la poética, la subjetividad y la percepción. Para que el individuo alcance esta subjetivización, debe construir una mirada crítica y proyectar un sentimiento sobre el territorio. La filosofía, la

3. Javier Maderuelo, El paisaje: génesis de un concepto (Madrid: Abada, 2005), 36. 
religión, la literatura o el arte son herramientas constructoras de pensamiento que nos permiten alcanzar dicha subjetivización. Como decía René-Louis de Girardin: "hay país y paisaje, como hay desnudez y desnudo"4.

El paisajista Javier Maderuelo explica que el paisaje es un concepto inventado, una construcción cultural. No es un lugar físico, sino el conjunto de una serie de ideas y sentimientos que elaboramos a partir del lugar. El paisaje precisa de un sujeto que lo interprete. Reclama un juicio estético y la proyección emocional del artista y del espectador. El paisaje se desarrolló de forma paralela a los avances pictóricos hasta convertirse en un género que cobrará particular fortuna a partir del siglo XVII5.

Sin embargo, a pesar de que el paisaje se gestase en la pintura, el primer atisbo del que tenemos conocimiento se encuentra en una epístola de Petrarca de 1336, donde narra su ascensión al monte Ventoux. Este texto se considera un punto de inflexión para el nacimiento del paisaje, y esto es así porque se denota un cambio de mentalidad en cuanto a la relación con la naturaleza: se aprecia una intención consciente de contemplación, una sensibilidad y una búsqueda de placer, así como una subjetivación. Además, coetáneamente, en el campo de la pintura se empezaron a vislumbrar los primeros indicios de protopaisaje en el Trecento italiano de la mano de Giotto. Si bien este vivió en una época aún muy temprana para hablar de paisaje, se denota cómo ya comenzó a cambiar los fondos dorados tan representativos del Trecento por tímidas incursiones de elementos naturales. Esto ha dado lugar a que muchos le declaren como el "fundador de la pintura de paisaje", pero esto resulta una afirmación muy reductiva, puesto que ningún cambio nace por la invención de un solo autor. Además, aceptando una premisa así, se menospreciaría toda la tradición del norte, la cual fue determinante para el surgimiento del paisaje occidental. Algunos de estos protopaisajes se encuentran, por ejemplo, en el famoso ciclo de Giotto La vida de San Francisco (h. 1300), en Asís, entre los que hay frescos como La donación de la capa; mas también entre artistas coetáneos como Ambrogio Lorenzetti con su Alegoría de la Redención (1338).

No obstante, pese a que las primeras pinceladas procedan de Italia, la tradición cultural de la pintura de paisaje occidental viene del norte de Europa, probablemente por estar menos influidos por las estrictas doctrinas de la religión, por las teorías del arte atadas a la herencia de la cultura clásica, por el lenguaje de la filosofía helénica y por las formas

4. Citado en Alain Roger, Breve tratado del paisaje (Madrid: Biblioteca Nueva, 2007), 22.

5. Maderuelo, El paisaje, 38. 
de la retórica latina ${ }^{6}$. Los primeros paisajes autónomos son obra de pintores como Alberto Durero, Lucas Cranach "EI Viejo", Albrecht Altdorfer, Joachim Patinir o Jacob van Ruysdael. Naturalmente, anteriores a estos primeros paisajes autónomos en Flandes, hallamos protopaisajes que también surgen en los fondos de las pinturas, los primeros ejemplos nos llegan del siglo XV, como, por ejemplo, Nacimiento de San Juan Bautista y San Juan bautizando a Cristo (h. 1420-40) de Jan van Eyck (1390-1441).

De entre todos estos artistas, quien debe ser especialmente considerado es Joachim Patinir (1480/1485-1524), comúnmente aceptado por los especialistas como el primero en crear un paisaje independiente y autónomo. Aunque pueda parecer exagerado emitir una afirmación tan absolutista, la novedad de Patinir no reside en ser la primera persona en retratar el entorno, sino en ser el primero en convertir a la naturaleza en tema protagonista otorgando a las figuras un lugar secundario, esta inversión de la jerarquía se aprecia muy bien en El paso de la laguna Estigia (1520-1524), por ejemplo. Sus contemporáneos ya le llamaban "pintor de paisajes". Aunque Patinir no partía de cero, lo que le desmarca de los otros pintores es que tuvo mucho éxito y creó "escuela". Y lo hizo en Amberes, donde pudo tener influencia, no como en el caso Albrecht Altdorfer quien, pese a que era coetáneo, trabajaba desde el valle del Danubio, desde donde no alcanzó una posición tan privilegiada e influyente ${ }^{7}$.

El siglo XVII constituye la consagración del paisaje porque es cuando el género tomó entidad y autonomía. En el foco del norte destaca primordialmente Jacob van Ruisdael debido a su versatilidad en la representación tan fiel y poética de la naturaleza, por la fuerza compositiva y por la introducción de innovaciones técnicas y temáticas que marcaron el desarrollo posterior, como, por ejemplo, el abandono del paisaje tonal. Su obra también destacó entre sus contemporáneos por presentar un imaginario que dirigía la atención a ideas contemporáneas acerca de la naturaleza y la sociedad². Entre sus obras célebres destaca, por ejemplo, Cascada en un paisaje montañoso (1660).

Por su parte el sur, también experimentará un siglo dorado de la mano de Claudio de Lorena y Nicolas Poussin, quienes retrataron la campiña romana con un clasicismo e idealismo exquisito. Puesto que, en contraposición con Flandes, la tradición latina estuvo

6. Dietmar Elger, Robert Rosenblum, y Fundación Juan March, La abstracción del paisaje: del Romanticismo nórdico al Expresionismo Abstracto (Madrid: Fundación Juan March, Ed. Arte y Ciencia, 2007), 268.

7. Alejandro Vergara, "La realidad transcendente de Patinir," YouTube, 2007, consultado el 19 de diciembre de 2018, https://www.youtube.com/watch?v=jln2ouq8Uhw.

8. John Walford, Jacob van Ruisdael and the perception of Landscape (New Haven: Yale University Press, 1991), 204. 
influenciada por la herencia grecolatina. Si bien ambos pintores pertenecen a la misma tradición, sendas trayectorias artísticas distan mucho la una de la otra. Mientras que el lorenés retrata una representación poética de la campiña romana, con sus luces cambiantes y sus asociaciones complejas, Poussin crea sus paisajes basándose en un pensamiento estoico y en cálculos lógicos. Por tanto, los medios de expresión adoptados por Claudio de Lorena serán radicalmente distintos a los de Nicolas Poussin?.

Por su parte, el siglo XVIII no significó una gran contribución técnica al desarrollo del paisaje, no obstante, la aportación indudablemente más importante al género durante este siglo, y, con ello, a la construcción del pensamiento paisajístico, se encuentra en la estética, en el pensamiento. Aunque nos resulte realmente imposible abordar este amplio tema en el presente artículo, consideramos conveniente recordar que se trata del Siglo de las Luces, de la razón. El signo del nacimiento de la estética contemporánea es la subjetivización de las cuestiones estéticas ${ }^{10}$. El foco se vuelve hacia el individuo, hacia el interior, y no hacia las cualidades formales del objeto. La consideración de la experiencia de los sentidos como forma de conocimiento creó el marco ideal para que ciertas ideas filosóficas pudieran desarrollarse y, con ellas, las categorías estéticas de lo pintoresco y lo sublime, tan determinantes para el género.

El siglo XIX constituye el gran apogeo del paisaje. Mas resultaría un desacierto defender, como en ocasiones viene ocurriendo, que el paisaje representa el "estilo romántico", pues no existe como tal. El Romanticismo no es un estilo establecido bajo una serie de normas, sino más bien se concibe como las prácticas artísticas resultantes de un conjunto de ideales comunes como pueden ser la importancia que se otorga en este periodo a la creatividad artística, a la originalidad, la individualidad o la autenticidad de la obra, así como a la integridad y a una nueva manera de entender la significación y la finalidad de las obras de arte y la función del artista"1". Estos son los principales intereses que comenzaron a popularizarse hacia 1800 y que son comunes a artistas tan dispares como Runge, Friedrich, Turner, Constable o Rousseau. Mas, aunque el paisaje no represente el estilo romántico, indudablemente este le otorgó una dimensión metafísica, le dotó de la categoría estética de lo sublime y, por consecuencia, lo consagró como "algo más que un género".

9. Anthony Blunt, Arte y Arquitectura en Francia. 1500-1700 (Madrid: Cátedra, 1983), 311.

10. Valeriano Bozal, ed., Historia de las ideas estéticas y de las teorías artísticas contemporáneas (Madrid: La balsa de la Medusa, 2010), 1: 32. 11. Hugh Honour, El Romanticismo (Madrid: Alianza Ed., 1989), 331. 
En el curso de este desarrollo a través de los siglos, el paisaje pasa de representar "cosas" a representar "impresiones". Así es cómo, con la llegada del Impresionismo, el paisaje atestigua un cambio de consciencia de la sociedad, o, mejor dicho, el nacimiento de una nueva consciencia ${ }^{12}$. Ahora, los artistas no se centran en lo que ven sino en cómo lo ven, en "la mirada". Debido al carácter experimental que adquiere el arte en este momento -recordemos que coetáneamente estaba desarrollándose la fotografía-, podríamos hablar del paisaje impresionista como un "instrumento de estudio" para investigar otras inquietudes, como pueden ser la luz y los efectos ópticos en la mirada. Los impresionistas se acercaron a la representación con un afán casi científico ${ }^{13}$.

Por su parte, la fotografía tuvo un papel determinante para el género del paisaje, aunque nos resulte verdaderamente imposible abordar aquí su interesante aportación, queremos reivindicar su papel tan frecuentemente ignorado. Con la llegada de la fotografía, la pintura abandona la figuración y la abstracción toma su lugar rechazando toda representación. De manera que el paisaje pictórico, que precisa de dicha figuración, entra en crisis. Es, entonces, la fotografía, en tanto que se presenta como fiel reproductora de la realidad, la que toma la responsabilidad de continuar con la tradición paisajística desde este momento y hasta el fin de las vanguardias en la década de los 60 (en la medida en que la modernidad supone una vuelta de espaldas a la naturaleza y que el paisaje muere en la abstracción que inaugura la pintura moderna). Algunos de los estilos que trabajaron el paisaje durante estos años son, por ejemplo, la fotografía pictorialista o la fotografía directa.

Así pues, somos conscientes de que podría parecer desacreditador hablar de "género" en el seno de las prácticas contemporáneas cuando fue precisamente ese rechazo al sectarismo añejo lo que motivó el fin de la era moderna. Al rescatar el paisaje en el contexto del género videográfico, no pretendemos reconstruir un discurso en la línea del academicismo deI XIX. Si no, revisar los géneros desde el pensamiento abierto e híbrido del siglo XXI, partiendo de la aceptación de la consanguinidad de las artes que caracteriza a la época "transmedia", estudiaremos las obras a partir de sus características y propósitos individuales para, así, devolverles su propia identidad. Los nuevos formatos -fotografía, videoarte, arte digital o cine- han heredado las particularidades de los géneros pictóricos. Y, aún hoy, a pesar de la hibridación de las artes, se distinguen con facilidad tales temáticas. Lo más interesante es que, frecuentemente, los artistas también

12. Kenneth Clark, Landscape into Art (Boston: Beacon Press, 1961), 131.

13. Juan David Chávez, "La exaltación mágica del paisaje," Iconofacto 9, no. 13 (2013), 131. 
han cuestionado, problematizado y transformado estos géneros. Por tanto, debemos tomar esta clasificación simplemente como una vía para abarcar el estudio de un tema tan amplio y no como una catalogación hermética.

\section{La praxis}

Desde el siglo XVII la naturaleza ha sido alarmantemente cosificada, lo que ha repercutido en la configuración de una nueva era geológica denominada Antropoceno. En 2016, un grupo interdisciplinar de expertos se reunió en el Congreso Internacional de Geología ${ }^{14}$ para valorar si la Tierra ha entrado en una nueva era geológica y podemos dar por concluido el Holoceno -que comenzó hace unos 11.500 años-. Acordaron que el Antropoceno es ya una nueva época geológica dentro del periodo Cuaternario ${ }^{15}$, que comenzó a mediados del siglo XX con los isótopos radiactivos de las bombas nucleares, cuyo rastro durará unos 4.500 millones de años, tantos como tiene la Tierra ${ }^{16}$.

La Tierra ha entrado en una nueva era que nosotros mismos hemos provocado y de la que muy probablemente seremos sus víctimas, porque la arrogancia humana no es motivo suficiente para olvidar que, antes de nosotros, la Tierra -por diversos motivos: meteoritos, glaciaciones...- ya ha experimentado cinco grandes extinciones. La última, y más famosa, la de los dinosaurios. Y, actualmente, según los expertos, estamos experimentando la sexta, puesto que las tasas que determinan el número de especies que mueren cada año supera cincuenta veces a las esperadas. Además, estas extinciones -excepto la de los dinosaurios- se debieron a cambios climáticos, la mayoría debidas al dióxido de carbono de las explosiones de volcanes, que originaron un rápido calentamiento global ${ }^{17}$. Hay una realidad que no puede obviarse y es que existe una huella geológica innegable de las acciones humanas sobre la Tierra.

14. Se trata del Congreso Internacional de Geología en su edición no. 35, celebrado en Ciudad del Cabo (Sudáfrica) entre el 27 de agosto y el 4 de septiembre de 2016. Puede encontrarse más información en el artículo publicado previamente al congreso a fin de divulgar sus primeros resultados: en Colin N. Waters et al., "The Anthropocene is functionally and stratigraphically distinct from the Holocene," Science, no. 351 (2016): 137-147 y en el comunicado emitido por el grupo "Media Note, Anthropocene Working Group," 2016.

15. Javier Salas, "Bienvenidos al Antropoceno: «Ya hemos cambiado el ciclo natural de la tierra»," El País, 9 de septiembre de 2016, consultado el 14 de enero de 2020, https://elpais.com/elpais/2016/09/05/ciencia/1473092509_973513.html.

16. Miguel Ángel Criado, "Antropoceno, la era en la que destruimos el planeta," El País, 27 de mayo de 2018, consultado el 15 de enero de 2020, https://elpais.com/elpais/2018/05/25/ciencia/1527257820_374244.html.

17. Alex Dunhill, "Pérmico, y otras extinciones masivas de las que el ser humano puede aprender," El País, 26 de julio de 2017, consultado el 15 de enero de 2020, https://elpais.com/elpais/2017/07/14/ciencia/1500023971_650028.html. 
Aunque el cambio empezó a gestarse con la Revolución Industrial, para afirmar que la Tierra entra en un momento geológico distinto -explica el geólogo A. Cearreta- tiene que haber un cambio "global y sincrónico". Por eso, aunque se propuso el año 1800 como fecha de inicio, se descartó porque su huella no llegó a todo el globo. Sin embargo, ahora se trata de un cambio en el comportamiento del planeta al completo. Provocado por los humanos y sus plásticos, sus emisiones de gases, sus industrias, la alteración de ecosistemas o la desaparición de biodiversidad, entre otras muchas acciones ${ }^{18}$. "Muchos de estos cambios son de larga duración, y otros son irreversibles", asegura el grupo en su resolución ${ }^{19}$. El Antropoceno es el resultado físico y evidente de la creencia del ser humano de estar por encima del resto de especies y salirse de las cadenas tróficas que garantizan el balance del planeta.

Hemos ido enseñando (...) que el ser humano es un animal inteligente y que esto es una lucha por la supervivencia. Y en esta lucha sobreviven los más fuertes o los que consiguen adaptarse mejor (...) Pero esto es un problema (...) Porque el ser humano ya hace siglos que salió del ámbito de la necesidad y entró en el ámbito de la libertad (...)Y, aunque en el campo de las artes sí hemos conseguido guardar la dignidad humana, no lo hemos hecho en la vida social y en la vida económica. Ahí sí, luchamos. Y nos animalizamos. Ahora esa es la tarea, llevar la dignidad humana a la economía y la sociedad ${ }^{20}$.

¿Qué tipo de sociedad se esconde tras estas acciones tan extremas? Parece evidente que esta sociedad no vive ni la misma realidad, ni tiene la misma conciencia que aquella que configuró la tradición paisajística de la era moderna. Es una civilización, sin duda, tecnológica. Todo es sonido e imagen: es audiovisual. Es rápido, mas efímero. El tiempo debe ser controlado por el individuo a su beneplácito. Es percepción, todo debe crear un impacto, una impresión que estimule los sentidos, y, sobre todo, debe moverse y sonar. Y si puede ser inmersivo, aún mejor. Es un mundo instantáneo, todo debe responder al "ya" y al "ahora", y preferiblemente bajo el control del consumidor. Es un mundo (pseudo)controlado, puesto que creemos controlar todo cuando en realidad somos nosotros quienes estamos controlados. Vivimos sumergidos en un pseudoliberalismo. Es un mundo donde se busca la realidad a través de lo irreal. Es un mundo amenazado por el cambio climático, con un ego y una arrogancia tan grande que ni siquiera se inquieta ante su propia autodrestrucción. Un mundo donde, hasta lo intangible, como el tiempo, tiene un precio. Todo se considera un producto apto para el mercadeo, aunque esto esté a punto de costarnos la propia existencia. A nivel de conciencia, es un mundo en el que las creencias ya no determinan conductas como lo hacían antaño, véase, por

18. Alejandro Cearreta en Salas, "Bienvenidos al Antropoceno."

19. Salas.

20. Joan Antoni Melé, "La dignidad humana, fundamento para una nueva economía," YouTube, 2 de noviembre 2017, consultado el 19 de enero de 2020, https://www.youtube.com/watch?v=1G2knM09P_w. 
ejemplo, la concepción de las sociedades indígenas. Ya se sabe que en la falta de respeto hacia la naturaleza no reside el avenimiento de males y catástrofes y que de ello no depende nuestra seguridad -en cuanto a lo que se refiere a una dimensión mágica o divina, claro-. Es al arrebatarle ese sentido "divino", cuando desaparece también el respeto. Puesto que la sensación de "control", de jugar a "ser Dios" mediante el avance tecnocientífico ha imperado hasta ahora, y, pensamos que seguirá funcionando en tiempos venideros. Nos hemos creído que la ciencia y la tecnología podrán siempre defendernos. Esta nueva conciencia "pseudoliberal" del individuo del siglo XXI se ha materializado en un sentimiento colectivo de emancipación olvidando que somos solo una especie más, y que vivimos en la naturaleza y no, como creemos, por encima de ella, citando a la antropóloga, ingeniera y activista ecofeminista Yayo Herrero: "Digamos que el gran pecado original de nuestra cultura es haber configurado una idea de progreso que considera que las personas pueden vivir emancipados de la naturaleza, de su propio cuerpo y de sus límites. En ese gran pecado original está lo que muchos denominan crisis civilizatoria, es decir, una civilización que cree que progresa cuando se destruye a sí misma"21.

Habida cuenta de ello: ¿Cómo se están reflejando estos patrones de comportamiento en el arte?, ¿cuál es el paisaje del Antropoceno?, ¿cómo el arte está plasmando esta nueva era? ¿con qué representaciones paisajísticas se identifican los sujetos de hoy conceptual y formalmente? El paisaje puede verse como algo añejo y tradicional, pero ha surgido un paisaje que sí se adapta a su tiempo y que se distingue de esos cuadros que podemos ver en grandes museos como el Louvre o el Prado. Han surgido artistas creando paisajes innovadores, desmarcándose de aquellos que en el nuevo milenio aún siguen manejando la estética dieciochesca, lo cual no pretendemos criticar aquí, sino, simplemente, reclamamos una cartografía actualizada del panorama para identificar las nuevas prácticas: paisajes que representan las preocupaciones de los individuos del Antropoceno mediante los códigos que utiliza la sociedad contemporánea. Manifestando preocupaciones de la población del siglo XXI, como, por ejemplo, el cambio climático, a través de los códigos y lenguajes que le representan, como la imagen en movimiento, la sensación de inmersión, el audiovisual o la apelación sensorial y emocional, puesto que "en la vida uno crece cuando es pequeño. Pero llega una edad en la que paras de crecer y maduras. Ya no podemos crecer más. Ni podemos, ni tiene sentido. Cuando en un cuerpo humano un grupo de células comienza a crecer más de lo que

21. "Cultura y Medioambiente," Cultura 18, 19 de abril de 2018, consultado el 13 de enero de 2020, http://www.rtve.es/alacarta/videos/ cultura18/video-cultura-medioambiente/4573100/. 
toca, y se olvidan de que forman parte de un organismo, a esto lo llamamos cáncer. Y acaban matando el organismo"22.

\section{Lukas Marxt: un paisaje post-apocalíptico}

Uno de esos jóvenes artistas que está contribuyendo a la creación de una nueva tradición paisajística es Lukas Marxt (Austria, 1983). Marxt es un videoartista que crea paisajes a partir de códigos narrativos, estéticos y conceptuales genuinamente contemporáneos. Su trabajo pretende mostrar la impronta de la acción humana en la Tierra. Busca retratar lugares que supongan un desafío para la supervivencia del ser humano. A Marxt le interesan paisajes remotos donde la naturaleza se presenta inmensa y poderosa, como retrata en Rising Fall $\left(2011,41^{\prime}\right)$, por ejemplo. Se trata de una obra para pararse a observar-desde la paciencia y la contemplación- el espectáculo que la naturaleza nos regala y que solemos pasar por alto. Con frecuencia, los videopaisajes, sirviéndose del recurso del tiempo que brinda el formato vídeo, utilizan esta herramienta para invitarnos a reflexionar sobre la velocidad de la vida contemporánea y apelar al detenimiento.

Sus obras se caracterizan por una cuidadísima estética, por la sensación de soledad, por planos que frecuentemente coquetean con la idea de lo sublime, y por unos paisajes que invitan a perderse para poder encontrarse. Como un auténtico paisajista de los de antaño, Lukas es un explorador: ha viajado al Ártico, ha entrado en una mina de uranio en Australia para cazar un doble eclipse, ha vivido en una plataforma petrolífera en mitad del mar del Norte, se ha perdido en los desiertos californianos, ha deambulado por las montañas canarias durante días y ha llegado hasta a las costas de Ghana. El trabajo de Marxt es un continuo diálogo con la naturaleza. Por ello, viaja hasta los rincones más remotos del planeta persiguiendo su deseo de perderse en la magnificencia de la misma a fin de reencontrarse a sí mismo. En estos videopaisajes la importancia de la búsqueda metafísica se presenta con notoria frecuencia, y las preocupaciones suelen girar en torno al autoconocimiento y al reencuentro con la propia esencia del individuo, rasgos característicos de la crisis de nuestra sociedad contemporánea: "A menudo visito [lugares] que me devuelven a mis necesidades básicas. Estas limitaciones son parte de un método de trabajo para usar mi percepción de manera más consciente e instilar instintos que no necesito en mi existencia normal. Se supone que es una explosión para

22. Melé, "La dignidad humana." 
demarcarme por un tiempo, para llevar una vida de acuerdo con mis propias reglas y las de la naturaleza"23.

A Lukas le interesa mostrar el mundo actual que ha resultado del impacto de la irresponsable acción humana. En su obra, habla de un mundo post-apocalíptico, que retrata, por ejemplo, en High Tide $\left(2013,7^{\prime}\right.$ ) donde no pasa nada, donde no vemos nada, porque no queda nada. Según él vivimos en mitad del post-apocalipsis ${ }^{24}$, muy relacionado con el concepto de "entropía" de Robert Smithson ${ }^{25}$. Es importante entender que lo concibe desde una perspectiva futurística, como aceptando el mundo actual y tratando de crear paisajes, nuevos paisajes. En el trabajo de Lukas se entiende que somos parte del cambio y reflexiona sobre de dónde venimos, dónde estamos y cómo lidiamos con ese cambio. Pero, aunque pueda parecer contradictorio, desde su aceptación también se vislumbra cierta melancolía de lo que un día fue y ya no. A veces aún recurre a la idea de la naturaleza poderosa e inmensa, como vemos en Low Tide $(2014,3$ ') o Reign of Silence $(2013,7$ ') donde somos "nada" ante la inmensidad.

Otra de las particularidades de su trabajo es la escala, lo que él llama "micro y macrocosmos". Para él la escala es como una metáfora de nuestra condición que depende del punto de vista. Lo pequeño o lo grande que puedes ser, depende de cómo lo observes. Esta idea la plasma en obras como Captive Horizon o Imperial Valley (2018) o (2015). Este último, Imperial Valley ${ }^{26}\left(2018,14^{\prime}\right.$ ) (Figs. 1 y 2 ) es, sin duda, su trabajo más maduro. Durante catorce minutos un dron sobrevuela la región Imperial, en la frontera con México, y nos muestra una vista aérea de la destrucción a la que se ha visto sometida el condado más al sur de California. A nivel formal, la perspectiva aérea es la protagonista. Esto es una novedad en la tradición del paisaje porque en la historia del paisaje pictórico no se utilizaron este tipo de vistas. Aunque consideramos oportuno precisar que estas no son nuevas: la fotografía ya las adelantó en el siglo XIX, entre las que destacan las vistas aéreas de Nadar. La estética general de Imperial Valley rompe con los códigos formales y narrativos tradicionales del paisaje.

23. Dominik Tschütscher, "Talents to watch: Lukas Marxt," Cinemanex, marzo de 2015, consultado el 20 de enero de 2020, http://www. cinemanext.at/talents-to-watch/lukas-marxt.

24. Esta información procede de la entrevista, aún inédita, que realizamos al artista en diciembre de 2017. Dicha entrevista será publicada en el trabajo de investigación que motiva este artículo.

25. Robert Smithson anticipó en la década de los sesenta las teorías del Antropoceno con su concepto de "paisaje entrópico" en Robert Smithson, "Entropy and the New Monuments," en Nancy Holt, ed., The Writings of Robert Smithson (Nueva York: New York University Press, 1979), 9-19.

26. Esta obra fue presentada por primera vez en la Berlinale de 2018. De momento no se encuentra disponible al público. El artista nos facilitó el acceso a su visualización de manera privada, así como al resto de su videografía también inédita. Un brevísimo extracto de la pieza puede ser visualizado aquí: https://vimeo.com/290890162 

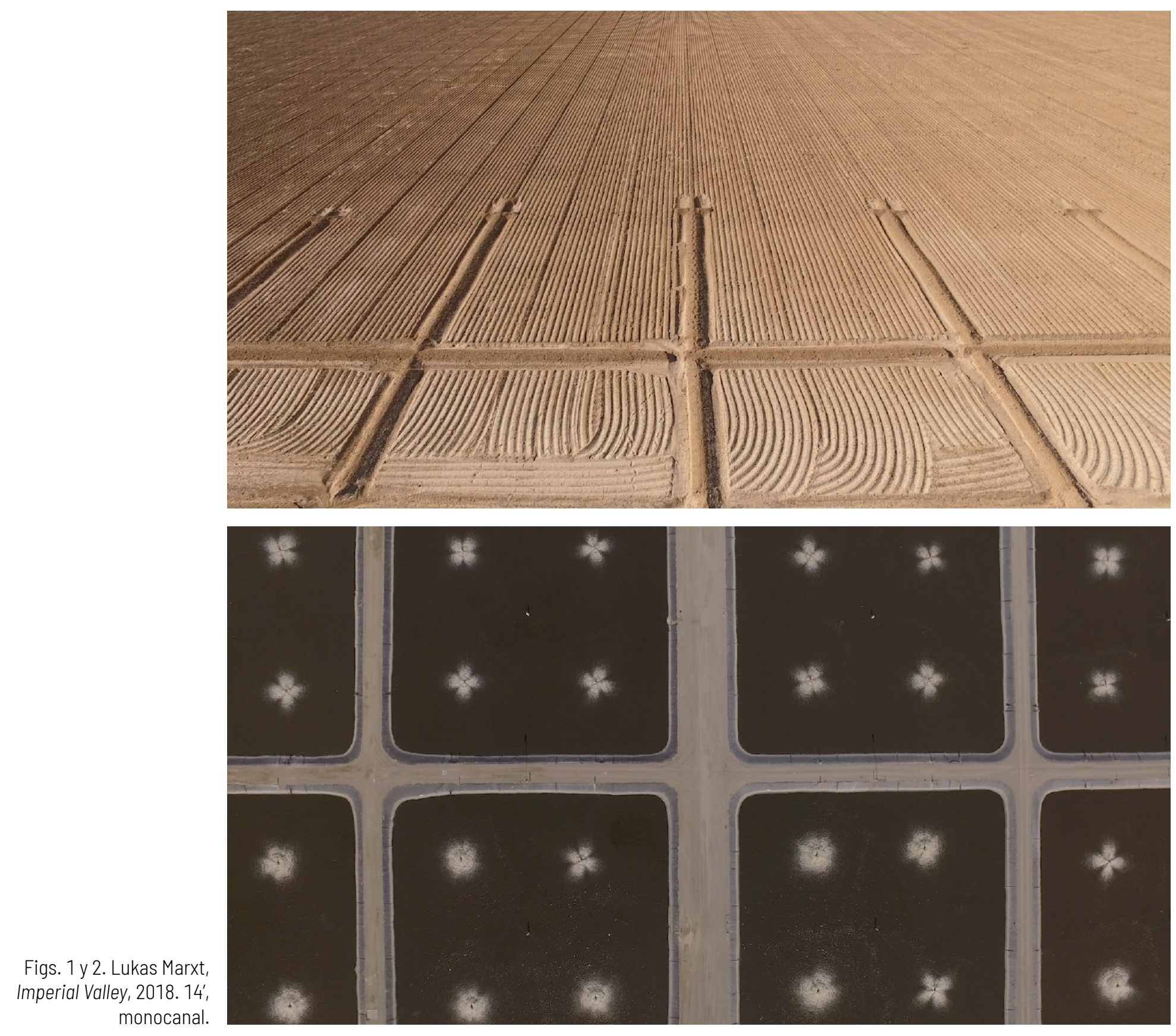

La obra comienza con una cámara aérea que avanza por un canal hasta llegar a unas balsas que a vista de pájaro conforman un dibujo simétrico de doce círculos. En este momento, el dron se detiene, como invitándonos a disfrutar del placer que la simetría causa al ojo. Luego presenta una sucesión de planos por las plantaciones, alternando líneas verticales y horizontales. El artista va acelerando y desacelerando la velocidad, así como estremeciendo o calmando el sonido. En un determinado momento, la cámara se detiene ante las líneas que parecen infinitas y empieza a dar vueltas en círculo, contraponiendo la rectitud con los movimientos circulares y llevándonos a perder la noción entre la realidad y la ilusión, pues al dar vueltas las mismas líneas se convierten en verticales u horizontales, dependiendo de la perspectiva, y a un cierto punto el ojo 
ya no alcanza a diferenciar qué ve, solo reconoce formas geométricas alternándose de forma ilusoria. La cámara sigue avanzando por la desolación hasta llegar a una granja, y-guiados por las líneas verticales- parece que avanzamos hacia el corredor de la muerte. Nos encontramos con unas estructuras abandonadas, ruinas de lo que un día fueron invernaderos, se trata de estructuras en forma de triángulo y, a continuación, hileras horizontales de semicírculos a través de las cuales la cámara avanza en una dirección que hasta ahora no había hecho: de forma horizontal hacia la izquierda, desubicándonos. Prosigue por unas plantaciones de palmeras, donde la propia "naturaleza" ha dibujado mediante el agua y en torno a las palmeras unas formas que vistas desde arriba crean la ilusión de ser flores. Tras esto, el artista introduce otro plano fijo con un dibujo simétrico de ocho cuadrados con una especie de cruces y el dron avanza por las hileras verticales precipitadamente hasta que la cámara y el audio van apagándose. Este recurso es empleado por el autor como una herramienta para calmar nuestras emociones y hacernos llegar en un estado sereno a una zona que parece un cementerio en ruinas. Son las estructuras en forma de cruz de los invernaderos, abandonadas y oxidadas. Cruces que en su mayoría ni siquiera siguen en pie. En este momento, la cámara se detiene, levanta "la mirada", contempla la desolación y la catástrofe de la estampa, y acaba la obra.

Se trata de un video en el que la luz es completamente natural; y el sonido ha sido detenidamente trabajado de forma electrónica para adaptarlo a las emociones que el autor deseaba trasmitir. Coordinándolo, además, con la aceleración o desaceleración de la moción de la imagen. Una de las características más destacables es que la obra está protagonizada por formas geométricas y por la belleza estética resultante de ellas.

El lugar representado, Salton Sea es el mayor lago de California, que ha existido desde 1906, creado por la gran crecida del río Colorado (1905), pero ahora es un completo desastre ecológico. Este solía ser un lugar de playas idílicas, hasta que a finales de los setenta fue destruido por un huracán, y en lugar de arreglarlo decidieron abandonarlo. La agricultura se apoderó del área, convirtiéndose en una de las zonas de mayor producción agrícola de EE. UU. El mayor problema se origina debido a que las plantaciones vierten al lago pesticidas y fertilizantes, y cuando el agua se evapora (el tamaño del lago aumenta o se reduce constantemente dependiendo de diversos factores) estos tóxicos se vierten a la atmósfera, a lo que hay que sumarle la contaminación de la industria del metal en la frontera mexicana. Un millón de peces han muerto y todas las ciudades de alrededor han sido abandonadas. Salton Sea está solo a dos horas de Los Ángeles y es un contenedor de residuos tóxicos. Se estima que en veinte años estará completamente seco y todas 
estas toxinas se habrán filtrado al aire, lo que supondrá que una parte importante de la población caiga enferma ${ }^{27}$.

Imperial Valley es una obra que retrata en códigos casi "sublimes" la belleza estética que es capaz de esconderse en la destrucción. Esta sirve como recurso para apelar al espectador y así intentar instaurar una conciencia sobre el problema. Las cicatrices del terreno, las ruinas, las alteraciones en la tierra... en conjunto con los colores, la ordenación y el acercamiento amable crean una gran sensación de placer visual y estético. La belleza colateral al desastre ecológico. Además, los planos muestran pulsiones de orden estético que nos remiten a la pintura abstracta. Las formas geométricas se convierten en protagonistas de la obra, testimonian la destrucción del ser humano y, a la vez, encuentran relación con las primeras representaciones de la naturaleza que realizó el ser humano, como las de las culturas prehistóricas, las precolombinas o la cultura celta, entre muchas otras. Formas que luego el Land Art también recupera. Estas adoptan un importante papel conceptual en Imperial Valley, donde se contrapone el origen y el fin: las formas más primigenias de representación de la natura son, a la vez, los únicos restos de la destrucción total. Paradójicamente, las formas que representan el principio de todo son, a la vez, las únicas huellas resultantes del fin. Pero, a pesar del mensaje, la obra crea un placer visual a partir de ellas, como ya hicieron los románticos al introducir las ruinas en sus pinturas. La obra finaliza con un último plano donde la tensión aumenta, el dron se detiene, el ritmo se pausa, el audio se calma, se levanta la vista, se contempla el valle y, de repente, toda esa belleza de la que veníamos disfrutando se torna en desastre y estrago. Un auténtico cementerio donde ni siquiera las cruces oxidadas siguen en pie.

\section{Gianfranco Foschino: el paisaje ecológico}

Gianfranco Foschino (Chile, 1983) es un videoartista chileno cuya obra gira en torno al deseo de entender el mundo y a la fascinación por los fenómenos naturales que conforman el motor de este planeta. Él defiende que estos pasan desapercibidos para las personas que vivimos encerradas en los núcleos urbanos, como las corrientes de agua, de viento, la formación de las nubes o los deshielos estacionales. Defiende que el conocimiento de la naturaleza y de sus fenómenos es la mejor forma de autoconocimiento. Y, para ello,

27. Esta información procede de la entrevista aún inédita que realizamos al artista en diciembre de 2017. Dicha entrevista será publicada en el trabajo de investigación que motiva este artículo. 
viaja a lugares remotos del planeta. Él también es un explorador. Su obra es una reflexión en torno a la naturaleza, sobre lo importante que es observarla y aprender de ella. Aunque su trabajo no parte de una premisa ecologista, sino ecológica ${ }^{28}$, debido al contexto en el que es recibida su obra, esta, automáticamente, torna su mensaje en una dimensión más activista, de concienciación. Es por este tipo de premisas que nos atrevemos a afirmar que, a pesar de que Foschino parta de una motivación científica, su obra tiene un impacto en la conciencia de la sociedad, tomando, sin premeditación, una dimensión socioactivista y que está estrechamente relacionada con las ideas antropocénicas que venimos tratando. "Nos estamos alejando [ de la naturaleza] desde la espiritualidad y eso genera conflicto. Los nativos siempre han estado en relación con la naturaleza y han armado su cosmovisión en relación a los fenómenos naturales y sus ciclos(...) El hombre se ha encargado de matar las culturas ancestrales, a los aborígenes, y con eso muere el conocimiento"29.

Según Foschino su intención es generar una conducta contemplativa y apreciativa por parte de los espectadores, construir umbrales y portales a través de los que viajar a partir de la imagen ${ }^{30}$. Hemos decidido introducir a Foschino en este artículo porque su trabajo representa un tipo de paisaje que no solo ha tomado en herencia la estética más tradicional del género del paisaje en sí, sino que, también, se sirve de los códigos formales y conceptuales genuinamente contemporáneos a la vez que los cuestiona. Lo hace, además, recuperando códigos de la pintura y de la fotografía. La contribución de Foschino a la construcción de una nueva tradición paisajista presenta una continua confrontación entre lo tradicional y lo contemporáneo.

Sus obras recuperan aspectos formales de la pintura, devolviendo la imagen en movimiento a lo que en esencia es: "imagen", y dotando de un papel secundario a los aspectos formales del formato audiovisual, que acostumbran a ser los protagonistas en las obras de videoarte. El éxito de su trabajo le ha llevado a exponer en numerosas bienales internacionales entre las que destaca la Bienal de Venecia, además, en dos ocasiones, en 2011 y 2014.

28. La ecología, a diferencia del ecologismo, es ciencia. Es la disciplina que estudia las relaciones entre los seres vivos del planeta y de estos con su entorno. Intenta explicar todos los procesos e interacciones que acaecen en la naturaleza. Mientras que el ecologismo es un movimiento de carácter social que se preocupa por la preservación de la misma.

29. Javiera Ide, "No te pierdas locus," Laderasur, 5 de octubre de 2016, consultado el 22 de enero de 2020, https://laderasur.com/estapasando/no-te-pierdas-locus-la-exposicion-de-naturaleza-de-gianfranco-foschino/ 30. Ide. 
Mediante sus "pinturas en movimiento", Foschino debate temas que tienen que ver con la metafísica tradicional, pero también con una metafísica genuinamente contemporánea. En Foschino el tiempo es el principal protagonista. Sus vídeos son pausados, obligan a detenerse y a pensar, a pausar el ritmo vertiginoso de la vida actual. Esta es una característica común de estos nuevos paisajes contemporáneos. La importancia del ejercicio de la contemplación como método para alcanzar el conocimiento ha sido menospreciado por la civilización contemporánea. Como comentábamos anteriormente, exigimos velocidad y efimeridad. Foschino, por su parte, "ralentiza" el tiempo y te obliga a detenerte. No obstante, hemos de aclarar, que uno de los rasgos característicos de su obra es la no manipulación del tiempo. Este transcurre a velocidad normal en sus trabajos, el problema está en que hemos acelerado nuestros tiempos a un ritmo tan vertiginoso que los naturales nos parecen ralentizados. Su obra se basa plenamente en la contemplación y en provocar un ejercicio de reflexión a partir de esta observación. Hemos olvidado el derecho y el deber del tiempo a la demora. Nuestra sociedad vive en una crisis de tiempo, porque en esta era postindustrial hasta lo ontológico se ha mercantilizado. Los videoartistas, sirviéndose del recurso del tiempo que brinda el formato vídeo, con frecuencia utilizan esta herramienta para llevarnos a reflexionar acerca de todo lo que pasa desapercibido cada día ante nuestro ojo. Es una crítica a la sociedad contemporánea que rechaza lo duradero, lo permanente, reclamando lo fugaz y lo momentáneo. Y lo autocontrolado. Una obra de videoarte no es un vídeo que se visualiza en un dispositivo que el usuario maneja a su beneplácito acelerando, desacelerando o deteniendo. Esta utilización del tiempo que los videoartistas hacen invita al espectador a una experiencia atípica para él con la imagen de naturaleza digital.

Las obras de Foschino comparten unos aspectos formales muy particulares: obras enmarcadas como un cuadro, una imagen en movimiento captada por una cámara siempre situada desde un punto de vista fijo, silencio y tiempo a velocidad real. Este eclecticismo crea un desconcierto en el espectador al reunir características formales de diversos formatos. Podríamos decir que Gianfranco Foschino pictorializa el tiempo y el movimiento, a diferencia de lo que el arte ha perseguido a lo largo de su historia, intentando dinamizar la imagen pictórica, como, por ejemplo, hicieron los futuristas en sus pinturas. Sus paisajes son auténticos lienzos de led. Esto facilita la relación del espectador con el videoarte, un acercamiento que no siempre es fácil. Sus obras se caracterizan por esa bidimensionalidad entre la quietud y el dinamismo. Por esa materialización de la moción de la imagen, devolviendo algo tan inmaterial como es el vídeo al concepto de obra como objeto fetiche. Nos resulta muy interesante el protagonismo que Foschino otorga a los marcos blancos, potenciando la idea del cuadro-objeto. Los 
cuadros recuerdan a la importancia que tiene el concepto de "marco" en la idea de "paisaje". Puesto que la idea de "límite" es un rasgo determinante para demarcar una "porción" de territorio, para diferenciar la vasta "naturaleza" del "paisaje". No obstante, para Foschino, el empleo del recurso del marco tiene que ver con una intención de esconder la pantalla, de esconder el dispositivo. La utilización del cuadro es relativo a la ilusión. Para el artista, toda obra debe generar intriga. Se trata de provocar una curiosidad. En el momento en el que el dispositivo desaparece, el espectador no sabe a lo que se enfrenta. Y el desconocimiento es el punto de partida para descubrir algo nuevo. El empleo de dicho recurso tiene que ver con cómo se percibe la obra. Una pieza que, a priori, cuando el individuo se percata de su presencia y se aproxima no conoce su naturaleza. Así, en un primer momento, no se sabe si es una fotografía o una pintura, pero luego se descubre que es un vídeo. Este recurso trabaja junto con las técnicas de transcurrir el tiempo a velocidad normal y la falta de narrativismo. Se trata de provocar preguntas en el espectador. Este "no saber" para Foschino es lo que invita a la detención. En el momento en el que se esconde el dispositivo, la obra se torna más ambigua. No se sabe qué es. Y ese desconocimiento resulta fundamental para querer descubrir.

Por otra parte, Foschino respeta la composición clásica del paisaje en sus obras, contribuyendo al pictorialismo y haciendo una alusión a la tradición moderna. Tal rasgo lo enfatiza mediante otros dos recursos: el punto de vista fijo y el silencio. Estos contribuyen a enfatizar esa reconciliación con la contemplación de la naturaleza y sus ciclos, principal preocupación del artista. Para Foschino el silencio posibilita otorgar a la imagen la facultad de expresar su esencia sin distracciones. Y para esto también es necesario un punto de vista fijo $^{31}$. Este tipo de características pueden reconocerse en trabajos como Fluxus (2010)(Fig. 3), La Esfinge(2016) o Fildes Bay (2016), obras que hablan de las corrientes de agua. Se trata de piezas que parten de la fascinación por el devenir de los fenómenos que mueven el planeta y donde la simple contemplación de los mismos es el motivo de la obra. Foschino concibe el arte como una forma de descubrir el mundo en el que habitamos. A él le interesa la ciencia, la ecología. Y pretende divulgar la idea de que el equilibrio natural está dado por la geología de la Tierra en la que los humanos son solo seres superficiales ${ }^{32}$. No obstante, si bien es cierto que la motivación del artista es la pura fascinación por la ciencia y por otorgar reconocimiento a estos fenómenos que pasan desapercibidos ante nosotros pero que generan la moción del planeta Tierra,

31. Información procedente de la entrevista aún inédita que realizamos al artista en enero de 2019. Dicha entrevista será publicada en el trabajo de investigación que motiva este artículo.

32. Información procedente de la entrevista aún inédita que realizamos al artista en enero de 2019. Dicha entrevista será publicada en el trabajo de investigación que motiva este artículo. 


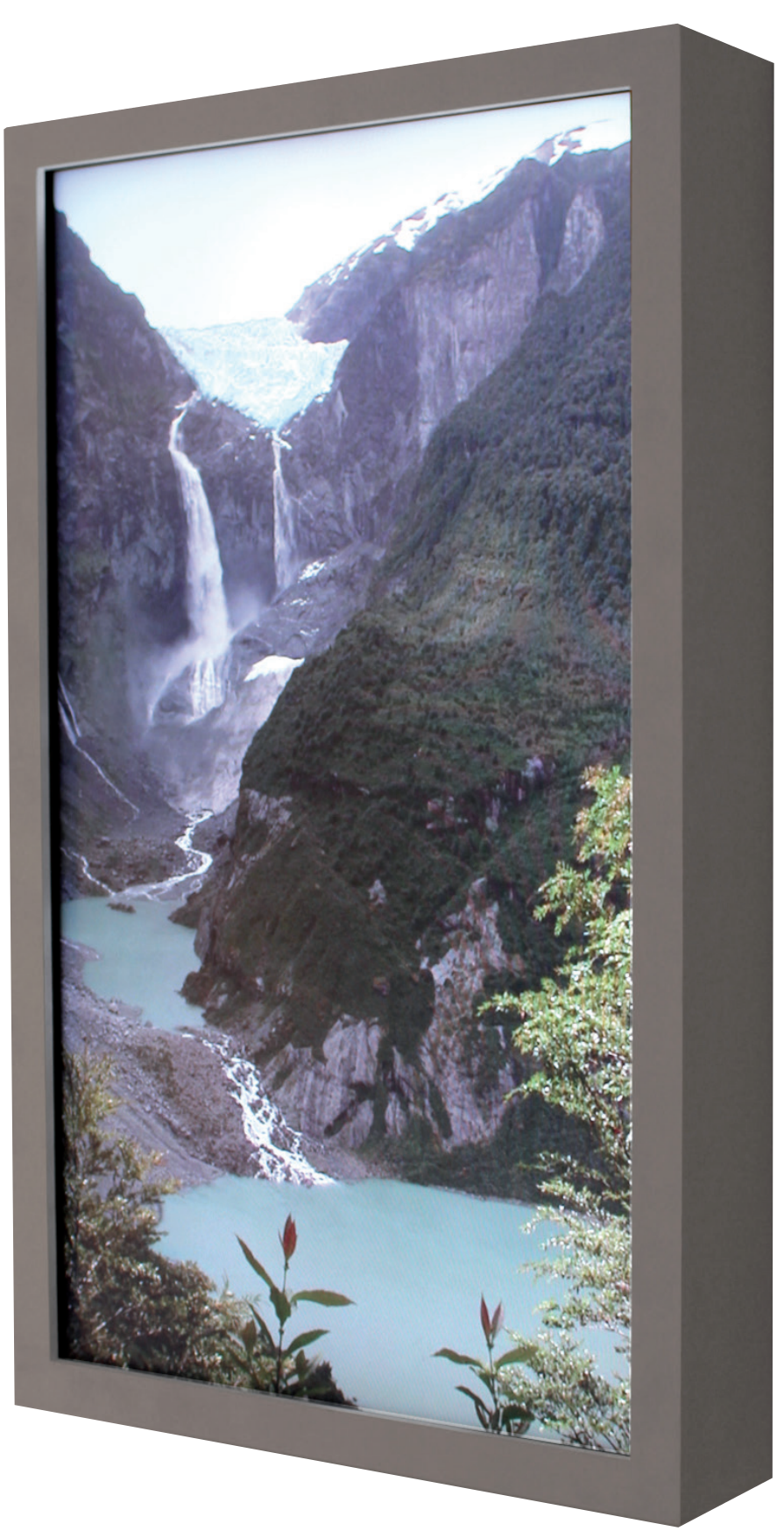

Fig. 3. Gianfranco Foschino, Fluxus, 2010. 8', HD, monocanal, led, silencio, loop.

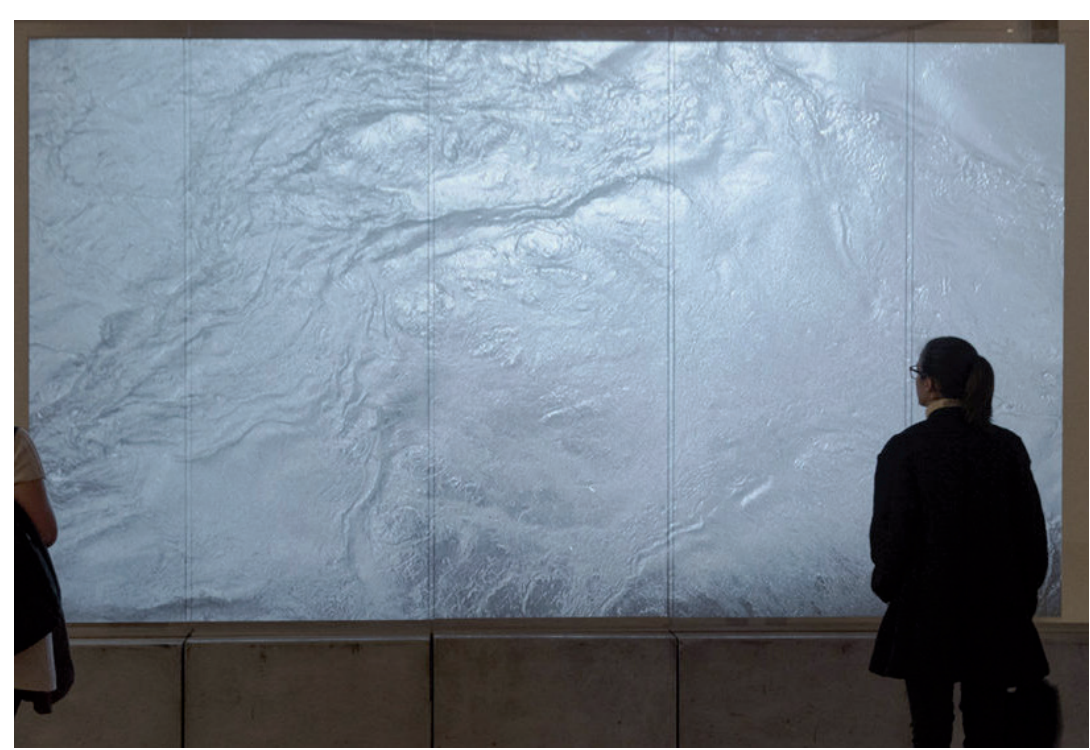

Fig. 4. Gianfranco Foschino, Ojos de agua, 2016. HD, videoinstalación hormigón y cristal, monocanal, silencio, loop.

lo cierto es que estas obras -especialmente las relacionadas con icebergs a la deriva o el deshielo-son recibidas en una sociedad que cada día se enfrenta a la realidad del Antropoceno, a la realidad de la destrucción del planeta. Por tanto, es inevitable que estos discursos ecológicos, a su vez, tomen una segunda lectura de índole ecologista, como la preocupación por el deshielo de la Antártida, lugar en el que fue realizada esta obra. Debido a las particularidades analizadas, los trabajos de Foschino pueden ser estudiados de forma transversal. Mas aquí introduciremos una pieza que se desmarca ligeramente de la dinámica general de su trayectoria.

Ojos de agua (2016) (Fig. 4) es una videoescultura de cristal montada sobre una gran base de hormigón que transporta al espectador a las aguas del río Futaleufú, a las aguas del deshielo antártico. Pese a que esta obra también presenta un punto de vista fijo, no presenta otras peculiaridades habituales como la composición tradicional de paisaje o el formato cuadro. Aunque, como al sólito, el tiempo transcurre a velocidad real, en esta obra el dinamismo parece incrementarse. Ojos de agua también presenta una gran ausencia de narratividad a la vez que esconde un fortísimo mensaje conceptual, el cual Foschino fundamenta en el poder otorgado a la estética. Apela a la pura sensorialidad y al imaginario colectivo 
para trasmitir su mensaje. Este se activa gracias al recurso del tiempo y a la interpretación que el espectador hace de la obra. Sus trabajos son como llamadas de socorro de la humanidad. Y esta, probablemente, es su pieza menos descriptiva y más conceptual. Enfatiza la poética visual y lo sensitivo. Apela a la reflexión, al detenimiento y a la lírica.

\section{Sonja Hinrichsen: paisajes censurados}

"Como artista siento la responsabilidad de dirigir la atención hacia problemas que nuestra sociedad intenta descuidar o negar, incluyendo el impacto medioambiental"33, de este modo define Sonja Hinrichsen su creación artística. El trabajo de esta artista alemana se centra normalmente en dibujos en la nieve de tal belleza que coquetean con la lírica pictórica. No obstante, su praxis es muy interdisciplinaria (dibujos, intervenciones en la naturaleza o videoinstalaciones). El trabajo de Hinrichsen examina ambientes -naturales o urbanos- y pretende remover conciencias para comprometer al espectador intelectualmente ${ }^{34}$. Su trabajo es principalmente inmersivo y apela a la experiencia. A Hinrichsen le interesa investigar el lugar y cómo nosotros lo percibimos. El tema de la percepción cobra particular importancia en las obras que estudiamos ${ }^{35}$. El interés de los artistas contemporáneos por las teorías de la percepción humana se evidencia con frecuencia en el paisaje contemporáneo, lo cual resulta un rasgo de identidad de estos nuevos paisajes respecto a los de la tradición anterior. El esfuerzo de los artistas por intentar entender mediante su arte cómo percibimos el mundo, cómo funciona la mente y cómo gestionamos toda la información que nos llega. Además, en lo que reguarda al género del paisaje, el papel determinante de estas teorías se enfatiza debido a que ese "entorno" supone la misma esencia del género.

Su obra The Three Gorges ${ }^{36}$ (2011)(Fig. 5) es una crítica audiovisual y metafórica a las políticas irresponsables de los gobiernos, en este caso, al gobierno chino por sus crímenes medioambientales. The Three Gorges es un trabajo muy reivindicativo que fue censurado por las autoridades chinas y que, aún desde la censura, se posiciona en contra de las autoridades por haber destrozado un espacio único a nivel natural y cultural para la historia del país. En el curso del río Yangtsé el gobierno decidió construir en los noventa la que a

33. Sonja Hinrichsen, "Artist Statement," consultado el 22 de enero de 2020, http://www.sonja-hinrichsen.com/artist-statement/. 34. Hinrichsen.

35. Las teorías de la percepción se popularizaron en la década de los sesenta gracias a las filosofías y religiones orientales que introdujeron el movimiento hippie, en especial en EE. UU., con nuevas vías de interpretación y pensamiento.

36. La obra puede visualizarse aquí: http://www.sonja-hinrichsen.com/portfolio-post/the-three-gorges-3rd-edition/\#7. 
Fig. 5. Sonja Hinrichsen, The Three Gorges, 2011. Videoinstalación.

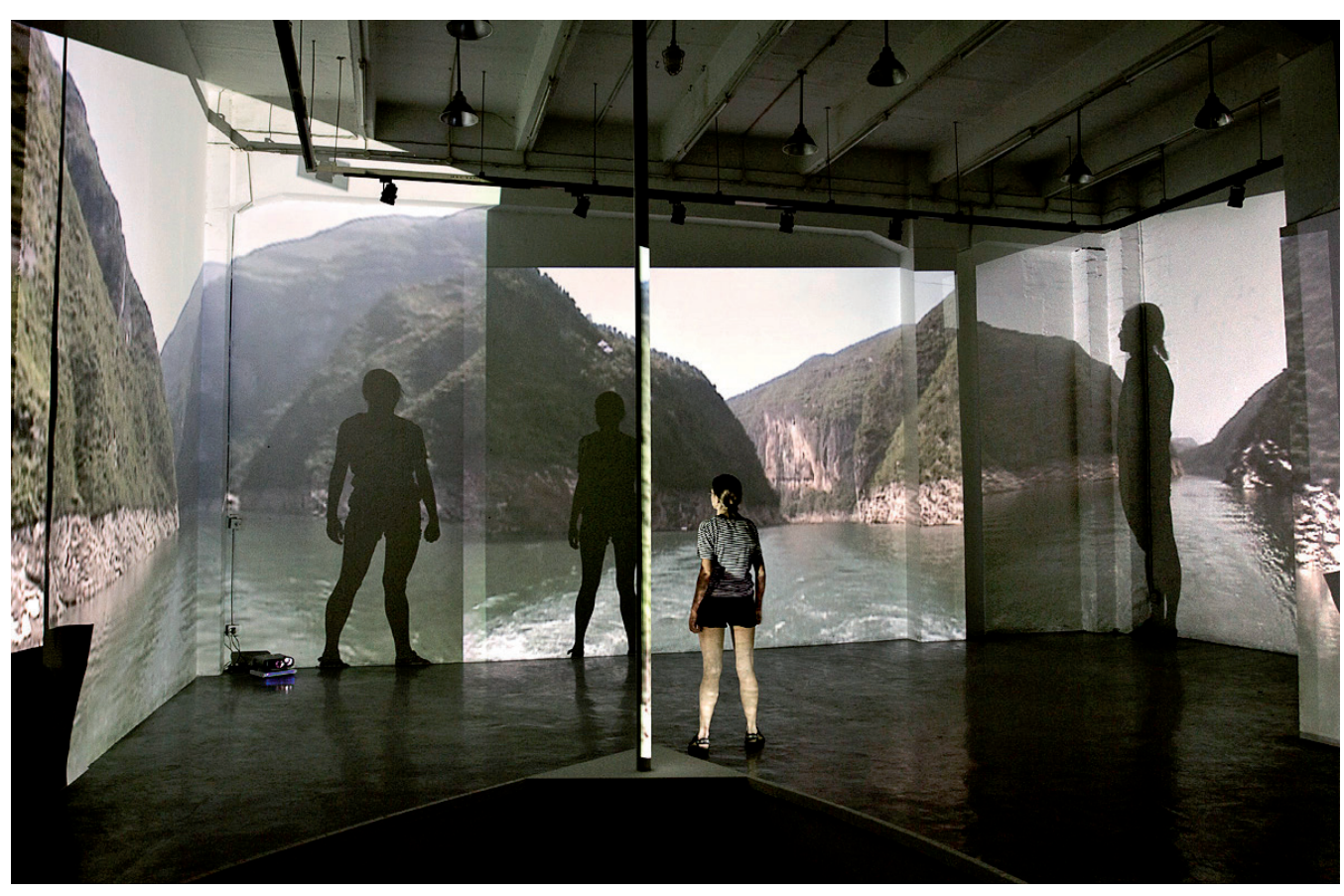

día de hoy es la mayor presa hidroeléctrica del mundo. Pese a que las autoridades se defienden diciendo que la construcción de esta presa se debió a la necesidad de regular las devastadoras inundaciones que sufrían los alrededores del río Yangtsé cada década, así como para aprovechar el potencial de la energía hidroeléctrica, la realidad es que esta urbanización descomunal de la zona se ha llevado por delante un paraje excepcional y miles de años de historia china. El río Yangtsé es el más grande de China y uno de los más grandes del mundo. Tiene un papel fundamental en la historia y la cultura de este pueblo. La naturaleza de los ríos es crecer y decrecer según los ciclos anuales. En cambio, los seres humanos decidieron establecer sus asentamientos a lo largo de este río y, para acabar con el problema que las crecidas causaban a la población, se decidió tomar una solución preocupantemente habitual para las civilizaciones: ir contra natura. La inundación de las tierras para la construcción de la presa provocó la pérdida de elementos del Paleolítico y del Neolítico, también tumbas ancestrales y tumbas de la aristocracia, asimismo obras de la dinastía Ming y Qing quedaron sepultadas bajo la línea de almacenamiento. En cuanto a las consecuencias ambientales, estas han sido devastadoras, alterando completamente la fauna y flora local. Además, el turismo se ha instalado en la zona y las cifras de visitantes se multiplican cada año, y con ello los ingresos económicos. Un ejemplo más de explotación del territorio. En torno a esta problemática nace esta obra tan reivindicativa, en la que Hinrichsen intenta visualizar el impacto de nuestras acciones sobre el planeta.

The Three Gorges es una videoinstalación de cuatro canales. Es una obra inmersiva. Las imágenes de tamaño gigante se extienden por toda la superficie de las paredes 
envolviéndonos. En el centro de la estancia encontramos una barca que simula las grandes naves que llevan a los turistas de paseo por el río. Las imágenes proyectadas simulan la vista que tendríamos desde el bote navegando por el río Yangtsé. SimuIan un paisaje irreal donde se aúnan cuatro ríos simultáneamente. La artista pretende mostrar cómo la construcción de la presa ha cambiado el paraje, pero también cómo ha desplazado a muchísima población de sus hogares y ha cancelado la memoria cultural de un pueblo. Este tipo de obras inmersivas son muy comunes en el videopaisaje. La sensación de inmersión y el reclamo de una realidad aumentada son recursos popularizados en la era contemporánea y que el arte incorpora. Las imágenes recrean lo que nuestros ojos verían desde esa nave que la artista sitúa en el centro de la estancia, como si estuviésemos navegando por el río. Es una obra que apela al empirismo.

Uno de los rasgos más interesantes de esta pieza es que la artista utiliza la posición de los proyectores para realizar una crítica al comportamiento de nuestros pueblos. Los proyectores de vídeo están situados de tal modo que cuando los visitantes entran en la estancia no pueden evitar crear una sombra sobre los paisajes. Con ello alude a la presencia permanente -ya inevitable- del ser humano en la naturaleza. La obra, en un principio, contaba con material adicional, como textos con reflexiones personales, hechos históricos, citas o entrevistas a locales, pero la galería solicitó a la artista que prescindiese de ello debido a los riesgos que conlleva la libre crítica a las autoridades en China. Inicialmente pensó en abandonar el proyecto, pero luego decidió que se quedaría y haría reflexionar a los visitantes a través de su arte en lugar de mostrar expresamente lo que debían pensar ${ }^{37}$. Llevaría a los espectadores mediante la recreación empírica a remover sus consciencias y a construir sus propias ideas críticas.

\section{Conclusiones}

Tras una revisión del panorama, hemos identificado numerosos artistas cuyos trabajos están configurando una nueva tradición paisajista genuinamente contemporánea. Nos resulta oportuno precisar que hemos estudiado muchos más artistas de los que en el presente artículo se muestran. Y tras cartografiar la escena artística, concluimos que, indudablemente, existe un amplio grupo de prácticas que pueden estudiarse en

37. Jennifer Hattam, "Artist's 'Three Gorges' Video Installation Takes Viewers Into a Disappearing Landscape," Treehugger, 5 de noviembre de 2011, consultado el 22 de enero de 2020, https://www.treehugger.com/culture/artists-three-gorges-video-installation-takes-viewers-into-disappearing-landscape.html. 
conjunto porque sus características de orden temático, estético, conceptual y narrativo coinciden. Por lo tanto, podemos hablar del surgimiento de una nueva tradición paisajística en el seno del arte contemporáneo. Y, en ella, de un paisaje ecológico, que teniendo en cuenta la realidad física de la era antropocénica, la crisis medioambiental y la crisis civilizatoria pretende visualizar y crear conciencia en la sociedad acerca del riesgo en el que nos encontramos. Estos paisajes se fundamentan en técnicas, conciencias, visiones y preocupaciones completamente nuevas que conciernen únicamente a la realidad de la sociedad de finales del siglo XX y principios del XXI, como, por ejemplo, puede ser el caso del calentamiento global o la técnica del vídeo. Además, aunque estas prácticas son reconocidas en el circuito del arte de manera individual, no han sido hasta ahora confrontadas ni estudiadas desde la ciencia en su conjunto. Sabemos que abordar un tema tan amplio e inexplorado es una tarea ambiciosa y de gran responsabilidad, por ello, somos conscientes de que aún nos queda mucho trabajo por hacer, pero esperamos que esta investigación sirva para dar a conocer la identificación de un nuevo paisaje y establezca las bases para que comencemos a dotar de reconocimiento a estas nuevas prácticas.

\section{Referencias}

\section{Fuentes bibliográficas}

Blunt, Anthony. Arte y Arquitectura en Francia. 1500-1700. Madrid: Cátedra, 1983.

Bozal, Valeriano, ed. Historia de las ideas estéticas y de las teorías artísticas contemporáneas. Vol. 1. Madrid: La balsa de la Medusa, 2010.

Chávez, Juan David. "La exaltación mágica del paisaje." Iconofacto 9, no. 13 (2013): 123-137.

Clark, Kenneth. Landscape into Art. Boston: Beacon Press, 1961.

Elger, Dietmar, Robert Rosenblum, y Fundación Juan March. La abstracción del paisaje: del Romanticismo nórdico al Expresionismo Abstracto. Madrid: Fundación Juan March, Ed. Arte y Ciencia, 2007.

Hinrichsen, Sonja. "Artist Statement." Consultado el 22 de enero de 2020. http://www.sonja-hinrichsen.com/artist-statement/.

---. "The Three Gorges." 2011. Consultado el 22 de enero de 2020. http://www.sonja-hinrichsen.com/portfolio-post/the-three-gorges-3rd-edition/\#7.

Honour, Hugh. El Romanticismo. Madrid: Alianza Ed., 1989.

Maderuelo, Javier. El paisaje: génesis de un concepto. Madrid: Abada, 2005.

"Media Note, Anthropocene Working Group." 29 de agosto de 2016. Consultado 13 de enero de 2020. https://www2.le.ac.uk/offices/press/press-releases/2016/august/ media-note-anthropocene-working-group-awg. 
Roger, Alain. Breve tratado del paisaje. Madrid: Biblioteca Nueva, 2007.

Smithson, Robert. "Entropy and the New Monuments." En The Writings of Robert Smithson, editado por Nancy Holt, 9-19. Nueva York: New York University Press, 1979.

Walford, John. Jacob van Ruisdael and the perception of Landscape. New Haven: Yale University Press, 1991.

Waters, Colin N., Jan Zalasiewicz, Colin Summerhayes, Anthony D. Barnosky, Clément Poirier, Agnieszka Galuszka, Alejandro Cearreta, Matt Edgeworth, Erle C. Ellis, Michael Ellis, Catherine Jeandel, Reinhold Leinfelder, J. R. McNeill, Daniel de B. Richter, Will Steffen, James Syvitski, Davor Vidas, Michael Wagreich, Mark Williams, An Zhishend, Jacques Grinevald, Eric Odada, Naomi Oreskes, y Alexander P. Wolfe. "The Anthropocene is functionally and stratigraphically distinct from the Holocene." Science, no. 351 (2016): 137-147.

\section{Fuentes periodísticas}

Criado, Miguel Ángel. "Antropoceno, la era en la que destruimos el planeta." El País, 27 de mayo de 2018. Consultado el 15 de enero de 2020. https://elpais.com/elpais/2018/05/25/ciencia/7527257820_374244.html.

Dunhill, Alex. "Pérmico, y otras extinciones masivas de las que el ser humano puede aprender." El País, 26 de julio de 2017. Consultado el 15 de enero de 2020. https://elpais.com/ elpais/2017/07/14/ciencia/1500023971_650028.html.

Hattam, Jennifer. "Artist's 'Three Gorges' Video Installation Takes Viewers Into a Disappearing Landscape." Treehugger, 5 de noviembre de 2011. Consultado el 22 de enero de 2020. https://www.treehugger.com/culture/artists-three-gorges-video-installation-takes-viewers-into-disappearing-landscape.html.

Ide, Javiera. "No te pierdas locus." Laderasur, 5 de octubre de 2016. Consultado el 23 de enero de 2020. https://laderasur.com/estapasando/no-te-pierdas-locus-la-exposicion-de-naturaleza-de-gianfranco-foschino/.

Salas, Javier. "Bienvenidos al Antropoceno: "Ya hemos cambiado el ciclo natural de la tierra»." El País, 9 de septiembre de 2016. Consultado el 14 de enero de 2020. https://elpais. com/elpais/2016/09/05/ciencia/1473092509_973513.html.

Tschütscher, Dominik. "Talents to watch: Lukas Marxt." Cinemanext, marzo de 2015. Consultado el 20 de enero de 2020. http://www.cinemanext.at/talents-to-watch/lukas-marxt.

\section{Fuentes videográficas}

"Cultura y Medioambiente." Cultura 18, 19 de abril de 2018. Consultado el 13 de enero de 2020. http://www.rtve.es/alacarta/videos/cultura18/videoculturamedioambiente/4573100/.

"IDFA 2018, tráiler, Imperial Valley." 20 de septiembre de 2018. Consultado el 20 de enero de 2020. https://vimeo.com/290890162. 
Melé, Joan Antoni. "La dignidad humana, fundamento para una nueva economía." YouTube, 2 de noviembre de 2017. Consultado el 19 de enero de 2020. https://www.youtube.com/ watch?v=1G2knM09P_w.

Vergara, Alejandro. "La realidad transcendente de Patinir." YouTube, 2007. Consultado el 19 diciembre de 2018. https://www.youtube.com/watch?v=jln2ouq8Uhw. 